\title{
Piano Key Weirs: the experimental study of an efficient solution for rehabilitation
}

\author{
O. Machiels $^{1,2}$, S. Erpicum ${ }^{1}$, B. J. Dewals ${ }^{1,3}$, P. Archambeau ${ }^{1}$ \\ $\&$ M. Pirotton ${ }^{1}$ \\ ${ }^{1}$ HACH unit, Department ArGEnCo, University of Liege, Belgium \\ ${ }^{2}$ Fund for Education to Industrial and Agricultural Research FRIA, \\ Belgium \\ ${ }^{3}$ Belgian Fund for Scientific Research F.R.S.-FNRS, Belgium
}

\begin{abstract}
The Piano Key Weir (PKW) is a particular geometry of weirs associating with a labyrinth shape and the use of overhangs, which reduce the basis length. The PKW could thus be directly placed on a dam crest. Together with its important discharge capacity for low heads (up to four times that of a Creager weir), this geometric feature makes the PKW an interesting solution for dam rehabilitation.

The PKW is a new type of weir, first designed in 2001 and built for the first time in 2006. Even if the first experimental studies confirmed its discharge capacities, there is still a lack of understanding of the flow behaviour upstream, along and downstream from this complex structure.

An experimental research, started in 2008 at the Laboratory of Engineering Hydraulics of the University of Liege, will provide contributions to the study of the flow behaviour on large PKW scale models, along with a geometric parameters analysis on models with variable geometries. These studies will enable one to define efficient and scientifically based design rules. This paper presents the strategy and main goals of this four-year study. These goals are also illustrated based on the first results obtained from experiments carried out on large scale models of PKW. The hydraulic behaviour of the structure is clarified based on measurements of water depths, pressures, velocities and discharges on each part of the weir.
\end{abstract}

Keywords: Piano Key Weir (PKW), experimental study, rehabilitation. 


\section{Introduction}

The Piano Key Weir is an original type of weir developed by Ouamane and Lempérière [1] to combine the interest of a labyrinth weir and overhangs used to facilitate its location on the dam crests (Figure 1). The first scale model studies showed that this new type of weir can be four times more efficient than a conventional Creager at constant head and crest length on the dam [1].

Studies have been carried out in different laboratories to characterize the influence of a number of geometrical parameters on the discharge capacity of the PKW [2-4]. Indeed, the PKW shows geometric specificities such as up- and/or downstream overhangs with variable width, inlet and outlet bottom slopes, which involve a large set of variable parameters (Figure 1).

The "PKW-element" is the basic structure of a PKW composed of a transversal wall, half an inlet and half an outlet. The main geometric parameters of a PKW are the transversal width of a PKW-element $W$, the weir height $P$, the number of PKW-elements $n$, the lateral crest length $B$, the basis length $B_{m}$, the inlet and outlet widths $a$ and $b$, the up- and downstream overhang lengths $c$ and $d$ and the wall thickness $e$.

The first real size PKW has been built by EDF in France during summer 2006 to increase the discharge capacity of the Goulours dam spillway [5]. With the experience from this first realization and the results of other experiments carried out on scale models, EDF developed the use of PKW for the rehabilitation of different dams in France. The second and third PKW were built on the St Marc dam during summer 2008 and during summer 2009 on the Gloriettes dam [6].

Up until now, the hydraulic design of a PKW is performed on the basis of experimental knowledge and scale model studies, modifying step by step an

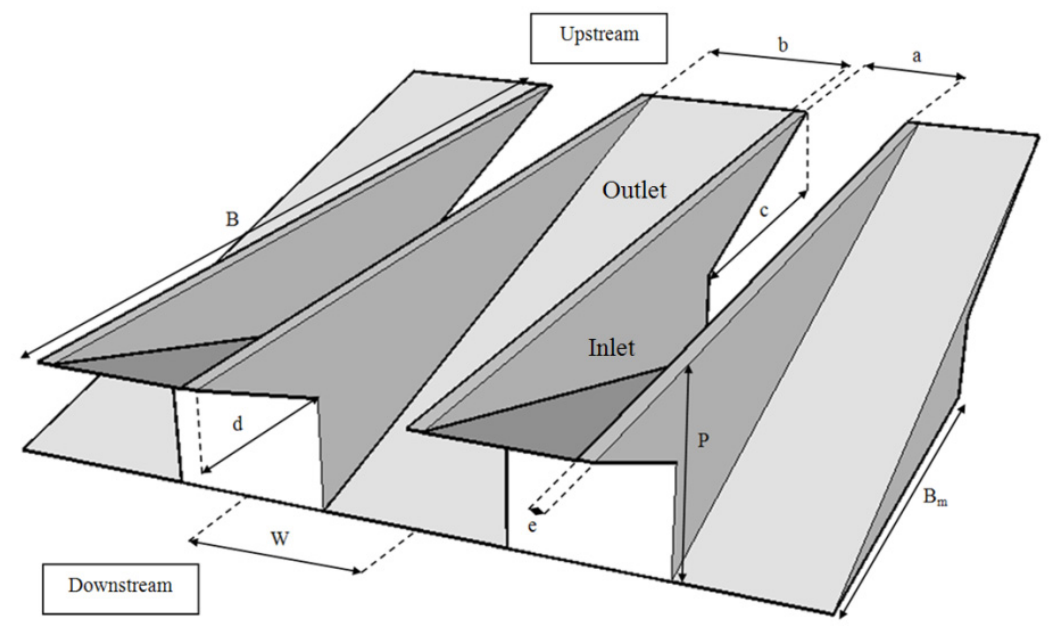

Figure 1: $\quad$ Sketch of a typical Piano Key Weir geometry and main geometrical parameters. 
initial geometry following the ideas of the project engineers [7]. There is thus a strong need for fundamental as well as applied studies on PKW to improve the understanding of the flow behaviour on this new type of weir and to set up efficient design rules to predict its discharge capacity. These are the reasons why a combined experimental and numerical study of PKW is undertaken at the Laboratory of Engineering Hydraulics of the University of Liege [8, 9].

\section{Hybrid modelling approach}

The first goal of the 4-year study presented in this paper is to enhance the understanding of the physics of the flows on a PKW to clearly define the benefits and limitations of this type of weir. This will be achieved by the exploitation of a large experimental model of PKW in a wide range of discharges.

In a second time, the study aims at determining the influence of the different geometrical parameters of the PKW on its discharge capacity. To achieve this goal, several scale models with variable geometries will be tested. In parallel to these experimental tests, numerical modelling will be performed to improve existing flow solvers and to help in defining the most important geometrical parameters of the weir.

Finally, the study will deliver analytical formulations of the discharge coefficient of PKW to be used during the design stage of new structures.

\subsection{Experimental facility}

A specific experimental facility made of a $7.2 \mathrm{~m}$ long, $1.2 \mathrm{~m}$ wide and $1.2 \mathrm{~m}$ high channel has been built to perform the scale model tests (Figure 2).

The channel is fed by two pumps delivering up to $300 \mathrm{l} / \mathrm{s}$ in an upstream stilling basin. The upstream entry of the channel is equipped with a metal grid and a synthetic membrane ensuring uniform inflow conditions.

Plexiglas plates on both channel sides allow to observe the flow patterns on the whole channel height at the location of the PKW model. Specific convergent structures allow reducing the channel width to the variable width of the tested models.

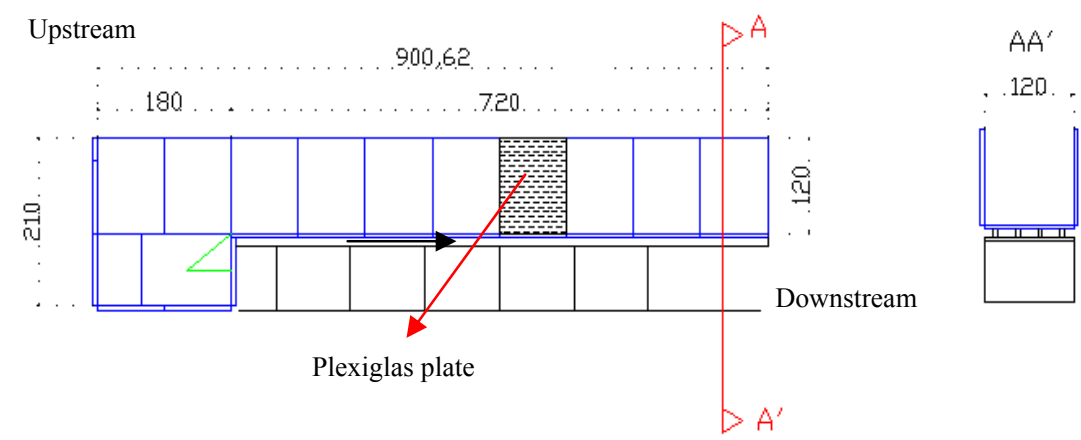

Figure 2: $\quad$ Experimental channel layout (dimensions in $\mathrm{cm}$ ). 


\subsection{Large scale model}

The first experiments have been carried out on a large scale model of a basic PKW geometry (Figure 3) to define precisely the transitions between the different flow types on the weir crests and to characterize these flow types in terms of velocity, pressures and flow patterns [8, 9].

To achieve this goal, 1.5 inlets and 1.5 outlets have been modelled. Thus, half an outlet and half an inlet are along the Plexiglas wall while the full alveoli are at the centre of the channel, without side walls effects.

Discharge and upstream head measurements are performed respectively with an electromagnetic flowmeter and a limnimeter with a precision of $\pm 1 \mathrm{l} / \mathrm{s}$ and $\pm 0.5 \mathrm{~mm}$. Dyes are used to identify different flow behaviours depending on upstream head variation.

\subsection{Velocity, pressure and water level measurements}

To perform the velocity, pressure and water level measurements, depicted in section 3.3 of this paper, six Pitot tubes [10] and a limnimeter with a vernier have been used (Figure 4).

The limnimeter enables the direct measurement of the free surface upstream of the weir and along the inlet. The precision of these measurements is $\pm 0.5 \mathrm{~mm}$.

The six Pitot tubes have been used in parallel across the channel section to measure the flow velocity and the pressure at different heights and different points upstream of the weir and along the inlet. The accuracy of these measurements is $\pm 1 \mathrm{~mm}$.

The measurements have been performed on 4 cross sections upstream of the downstream crest $(X=0)$ of the PKW $(X=0.11 \mathrm{~m}, 0.32 \mathrm{~m}, 0.53 \mathrm{~m}$ and $0.74 \mathrm{~m})$. Measurements points have been defined on the whole width of the channel with a step of $3.3 \mathrm{~cm}$ and on 4 elevations: $Z=0.05 \mathrm{~m}, 0.25 \mathrm{~m}, 0.55 \mathrm{~m}$ and $0.75 \mathrm{~m}$ from the bottom of the channel. There are thus 117 points of measurement (Figure 5).

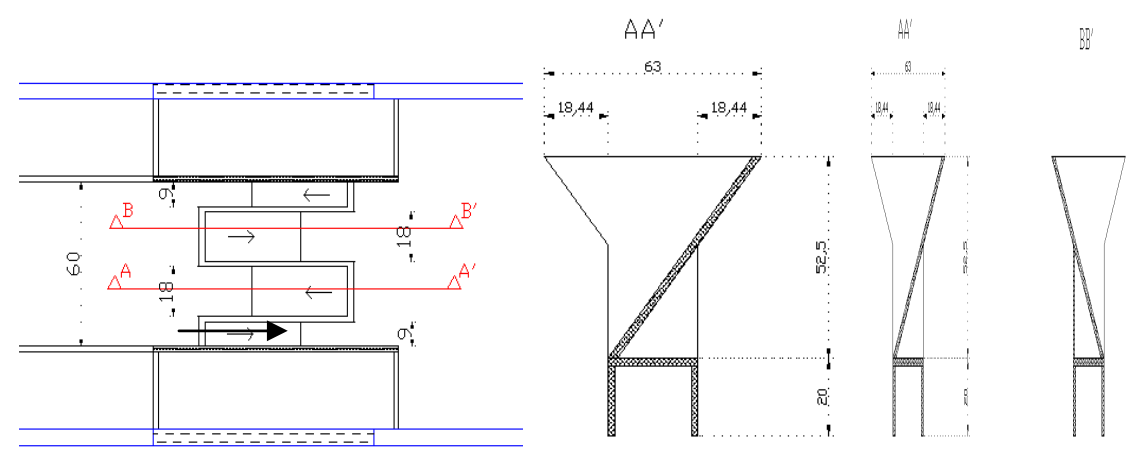

Figure 3: $\quad$ Large scale model layout (dimensions in $\mathrm{cm}$ ). 

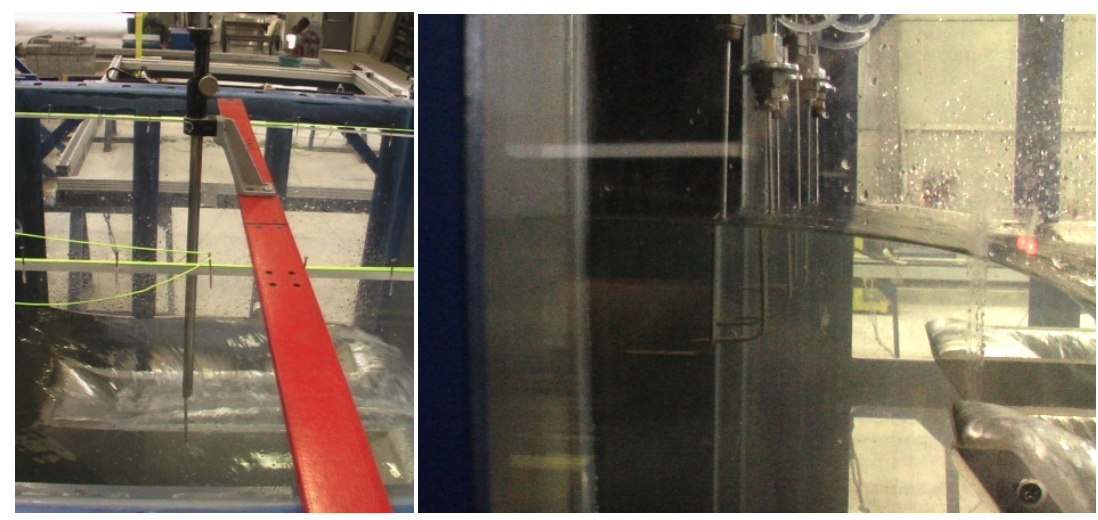

Figure 4: Measurement equipment: limnimeter with vernier (left) and pitot tubes (right).
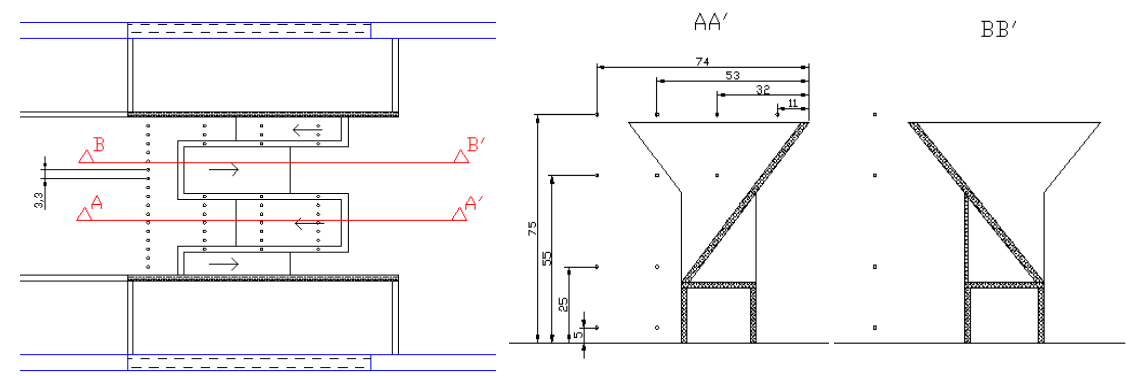

Figure 5: Location of measurement points with pitot tubes.

\section{Results}

\subsection{Release capacity}

Because of the complexity of the PKW geometry, the discharge capacity is a function of many geometric parameters. It is of common use to express, as in eqn (1), the discharge $Q$ on a PKW under a water head $H$ as a function of the total weir length $W_{T}$ on the dam crest.

$$
Q=C_{w} W_{T} \sqrt{2 g H^{3}}
$$

All the weir geometric specificities are thus contained in the discharge coefficient $C_{w}$ [3].

The non-dimensional head / discharge coefficient curve of the model has been measured during the two first test periods $[8,9]$. This curve is completed by new measurements performed during the third test period depicted in this paper (Figure 6). The error bars show the influence of the discharge measurement accuracy on the $C_{w}$ values. 


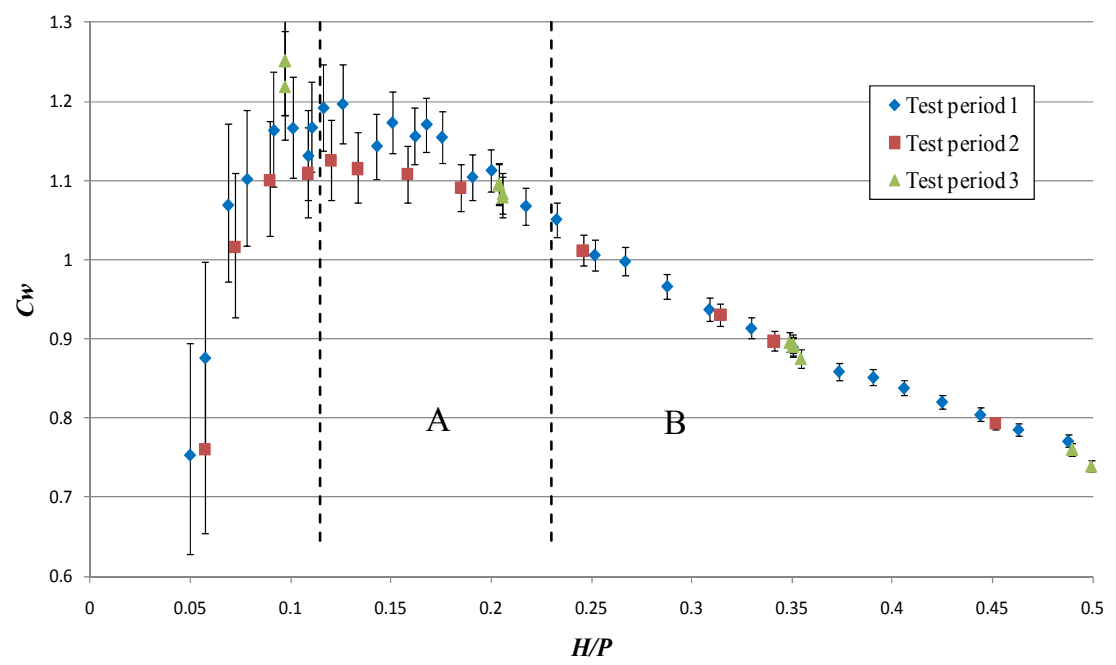

Figure 6: Non-dimensional head/discharge coefficient relation measured on the physical model.

This curve is relatively close to the curves presented by Ouamane and Lempérière [3] for non-optimal characteristics of PKW. Indeed, the geometry of the model has been defined to emphasize the differences between various flow types on the weir by increasing the slopes of both inlets and outlets, thus globally decreasing the PKW efficiency.

However, for low water heads $(H / P<0.15)$, there is an important decrease in the discharge coefficient compared to the Lempérière results. The explanation of this phenomenon is the influence of the crest thickness and shape [8].

\subsection{Stream lines}

The second test period permits to determine the stream lines on the PKW depending on the upstream head, by tracking of a colouring agent. To achieve this goal, 12 different heads, from $H / P=0.05$ to 0.45 , have been studied considering 25 injecting points of the colouring agent [9].

The differentiation could be done between low heads $(H / P<0.2)$ and high heads $(H / P>0.2)$ flow characteristics in terms of stream lines repartition along the inlet (Figure 7). For low heads, the stream lines are rather homogeneously distributed along the whole weir crest. However, for high heads, the stream lines distribution appears less satisfactory. Indeed, the downstream crest of the inlet is importantly supplied, always by the bottom stream but also by streams coming in front of the inlet with important velocity. The upstream crest of the outlet is only supplied by the surface stream. Finally, the lateral crest is poorly supplied by streams coming front of the outlets, under the crest level.

The transition between these main stream lines sketch corresponds to the transition between a flat free surface line to a ripple free surface line along the 


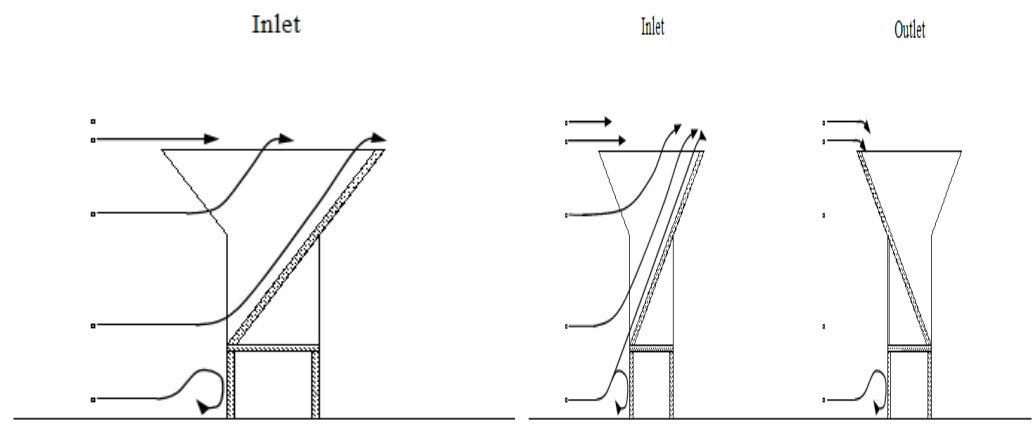

Figure 7: Stream lines along the inlet for low $(H / P<0.2-$ left $)$ and high heads $(H / P>0.2$ - right $)$.

PKW [9]. It corresponds also to the beginning of the decrease in the discharge coefficient with head (Figure 6). These two phenomena are directly linked to the variation of the stream lines distribution [9].

\subsection{Free surface, velocity and pressure profiles}

During the third test period, free surface, velocity and pressure profiles have been measured upstream of the weir and along the inlet. Four head ratios have been studied to characterize the flow behaviour: low heads $(H / P=0.1)$, high heads $(H / P=0.35$ and 0.5$)$ and transition zone highlighted by the stream lines study $(H / P=0.2)$.

The free surface measurements show the transition between the flat free surface for low heads $(H / P=0.1)$ and the ripple surface for high heads $(H / P=$ 0.35 ) (Figure 8 ). This phenomenon is accentuate for $H / P=0.5$. It doesn't appear on Figure 8 because the lowest point of the free surface moves upstream, inbetween the measurement points, observed during the test.

The pressure profiles are close to hydrostatic along the side wall as well as in the middle of the inlet except in particular points (Figure 8). In places where the stream lines are closer [9], an over-pressure zone can be observed compared to the hydrostatic profile. It is the case in the part of the flow in front of the angles near the inlet entrance (Figure 8 -Zoom). This over-pressure increases when the upstream head rises.

The velocity profiles for low heads $(H / P=0.1$ and 0.2$)$ are relatively uniform along the side wall as well as in the middle of the inlet (Figure 9 and Figure 10). This illustrates the homogeneity of stream lines repartition. For higher heads $(H / P=0.35$ and 0.5$)$, the velocity increases in the middle of the inlet (Figure 9 and Figure 10). Closer is the measurement point from the downstream crest, higher is the velocity. This illustrates the stream lines concentration in this zone. For $H / P=0.5$, negative velocities are observed near the side walls at the inlet entrance (recirculation zones). 


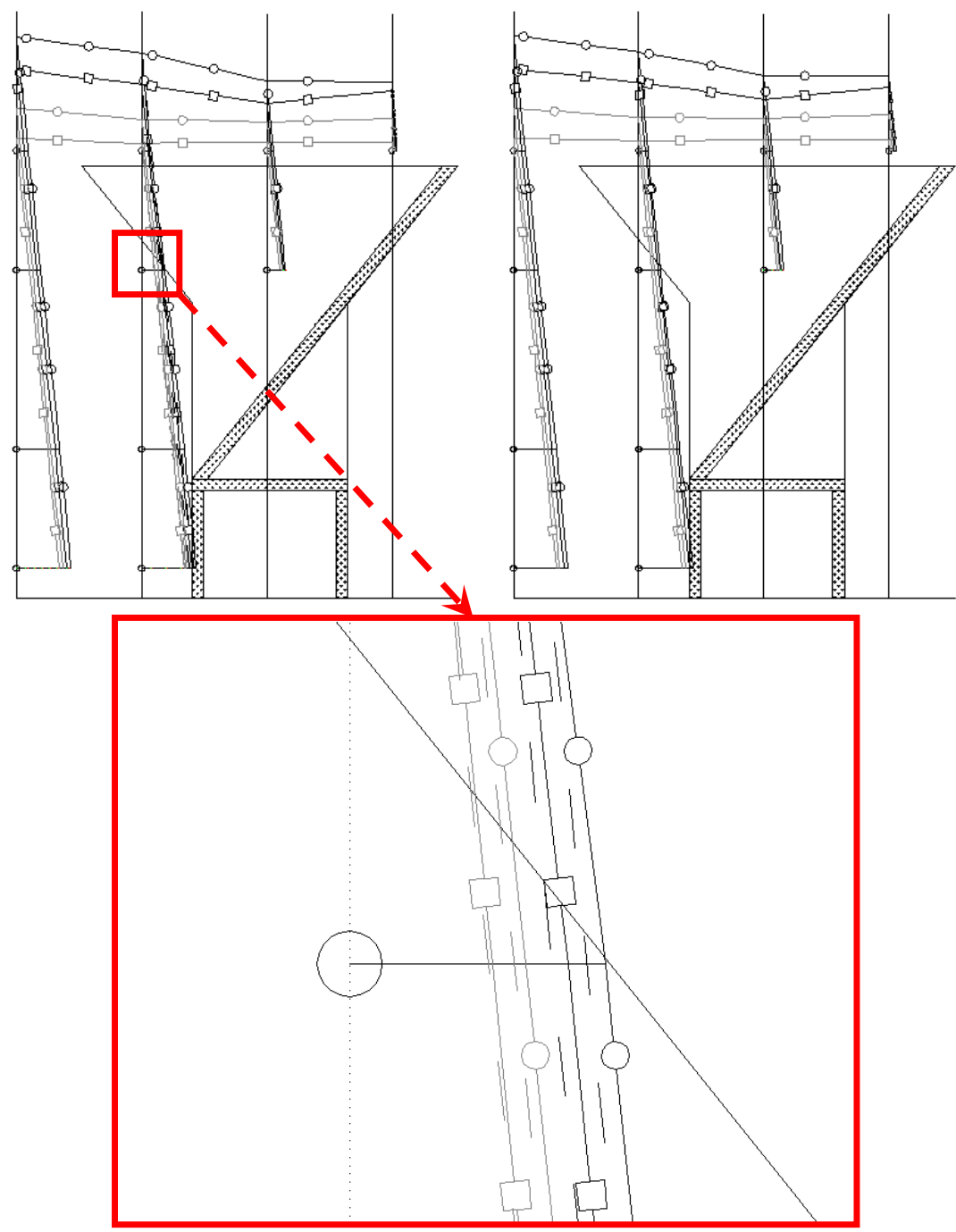

Figure 8: $\quad$ Free surface and pressure profiles in the middle (right) and near the side (left) of the inlet (dark/circle - $H / P=0.5$; dark/square $H / P=0.35$; grey $/$ circle $-H / P=0.2$; grey/square $-H / P=0.1$ )

The recirculation zones observed along the side walls of the inlet enables a better understanding of the flow behaviour on PKW. Indeed, the size of this recirculation increases with the upstream head. This zone, combined with an important bottom slope, reduces the effective section of the inlet. This reduction of section causes an important concentration of the stream lines and so increases velocities in the middle of the inlet entrance (Figure 10). A control section, visible with the ripple free surface, appears when velocities become too important $\left(\mathrm{Fr}^{2}>1\right.$ - Figure 11). This control section moves upstream with the 

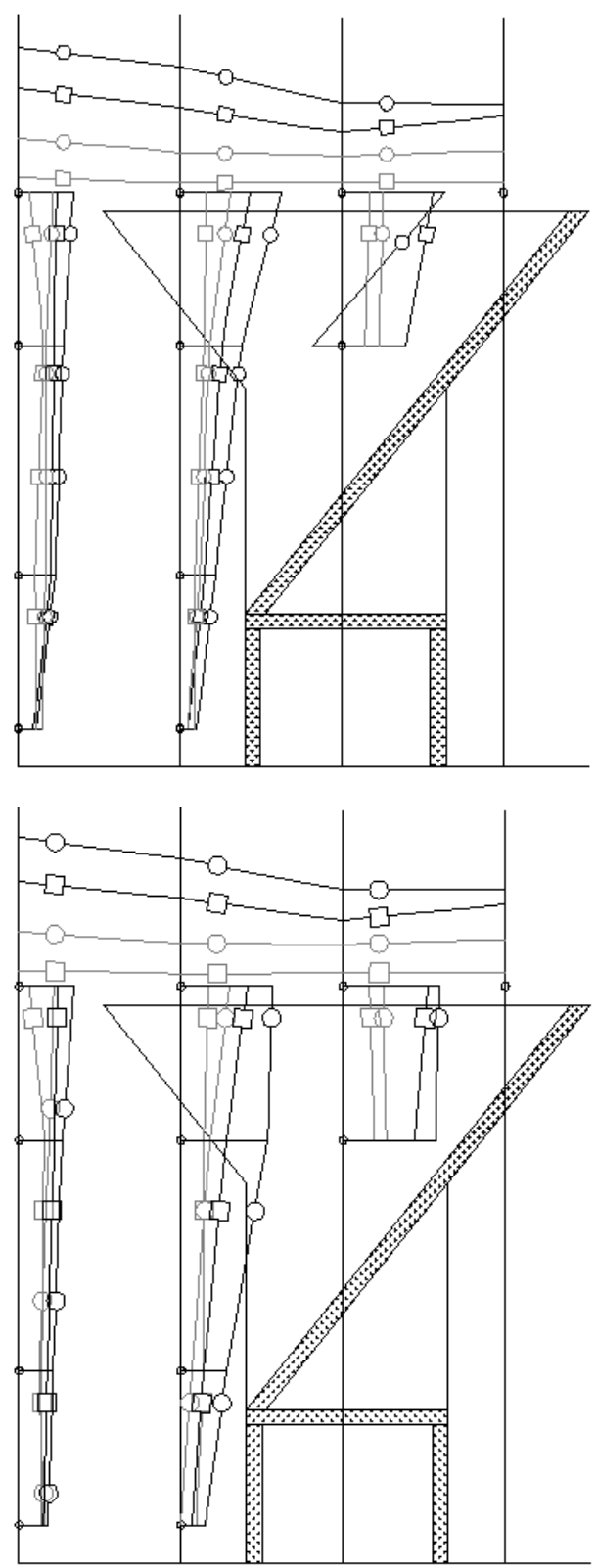

Figure 9: $\quad$ Free surface and velocity profiles in the middle (lower figure) and near the side (upper figure) of the inlet (dark/circle $-H / P=0.5$; dark/square - $H / P=0.35$; grey/circle $-H / P=0.2$; grey/square $H / P=0.1)$. 
104 Flood Recovery, Innovation and Response II

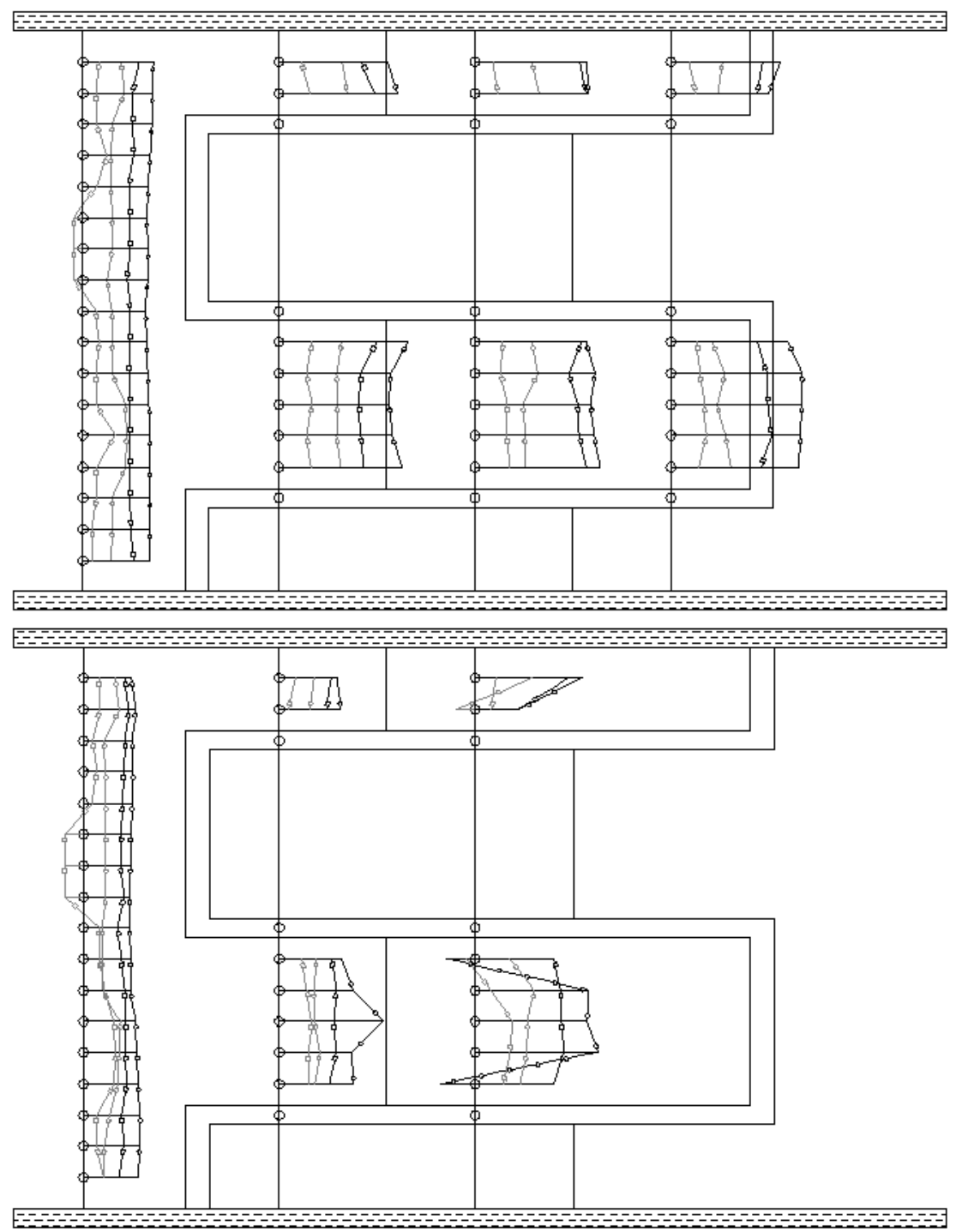

Figure 10: $\quad$ Velocity profiles over $(Z=75-$ upper figure) and in $(Z=55-$ lower figure) the PKW (dark/circle $-H / P=0.5$; dark/square $-H / P$ $=0.35$; grey $/$ circle $-H / P=0.2$; grey/square $-H / P=0.1)$. 


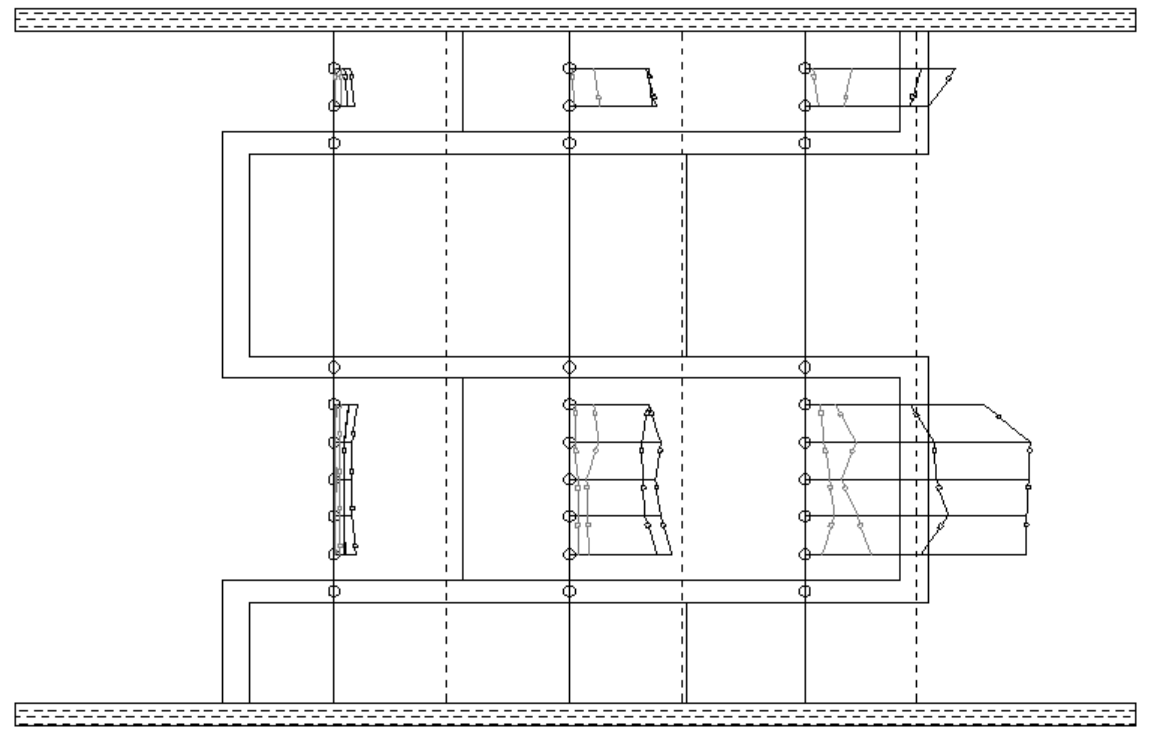

Figure 11: $\quad$ Froude $\left(F r^{2}\right)$ profiles over the PKW (dark/circle $-H / P=0.5$; dark/square - $H / P=0.35$; grey/circle $-H / P=0.2$; grey/square $H / P=0.1$; broken lines $\left.-F r^{2}=1\right)$.

rising head where the water height is more important, reducing velocities. The discharge capacity decreases more and more importantly (Figure 6 - Zone A). Finally, for higher heads the control section stays directly at the entrance of the inlet. The discharge capacity decreases less importantly to tend to a limit value (Figure 6-Zone B).

These observations enable to explain the interest of increasing the inlet width $[3,4]$, the inlet slope or the inlet height [3, 11] (using crest extension by example) to increase the inlet cross section. This requires higher velocities, involving higher upstream heads, for a control section apparition. Limiting this apparition for higher heads, the discharge capacity of the weir is improved. It also explains the hydraulic interest of the only use of upstream overhangs [3], what reduces the inlet length and so the influence of the control section. Finally, the use of a non rectangular shape of the front part of the upstream overhangs [11] decreases the recirculation zone size what increases the discharge capacities.

\section{Conclusions}

In order to improve the understanding of the flows over PKW, an experimental study is currently undertaken. A large scale model has been built and is under exploitation to characterize the different flow types on the weir crests. This experimental program will be completed by numerical modelling. 
The on-going tests enable to confirm and explain by measurements the influence, on the discharge capacity of PKW, of the stream lines profiles above the weir and in the inlets. These measurements help in the understanding of the hydraulic behaviour of the PKW by highlighting the effect of recirculation zones appearing for high heads and creating a control section in the inlet. This control section seems to be the main cause of the discharge coefficient decrease with the head.

The observations developed in this paper help in the understanding of former empirical relations.

\section{References}

[1] Ouamane, A. \& Lempérière, F., The piano keys weir: a new cost-effective solution for spillways. Hydropower \& Dams, 2003(5).

[2] Hien, T.C., Son, H.T. \& Khanh, M.H.T. Results of some piano keys weir hydraulic model tests in Vietnam. in 22ème congrès des grands barrages. 2006. Barcelona: CIGB/ICOLD.

[3] Ouamane, A. \& Lempérière, F., Design of a new economic shape of weir, in Dams and Reservoirs, Society and Environment in the 21st Century. 2006.

[4] Machiels, O., Erpicum, S., Archambeau, P., Dewals, B.J. \& Pirotton, M. Analyse expérimentale du fonctionnement hydraulique des déversoirs en touches de piano. in Colloque CFBR-SHF: "Dimensionnement et fonctionnement des évacuateurs de crues". 2009. Paris, France.

[5] Laugier, F., Design and construction of the first Piano Key Weir (PKW) spillway at the Goulours dam. Hydropower \& Dams, 2007(5): p. 94-101.

[6] Bieri, M., Ribeiro, M.L., Boillat, J.-L., Schleiss, A., Laugier, F., Delorme, F. \& Villard, J.-F. Réhabilitation de la capacité d'évacuation des crues: Intégration de "PK-Weirs » sur des barrages existants. in Colloque CFBRSHF: "Dimensionnement et fonctionnement des évacuateurs de crues". 2009. Paris, France.

[7] Ribeiro, M.L., Albalat, C., Boillat, J.-L., Schleiss, A.J. \& Laugier, F. Rehabilitation of St-Marc dam. Experimental optimization of a piano key weir. in 32th Congress of IAHR. 2007. Venice, Italy.

[8] Machiels, O., Erpicum, S., Archambeau, P., Dewals, B.J. \& Pirotton, M. Large scale experimental study of piano key weirs. in 33rd IAHR Congress. 2009. Vancouver, Canada.

[9] Machiels, O., Erpicum, S., Archambeau, P., Dewals, B.J. \& Pirotton, M. Experimental study of the hydraulic behavior of Piano Key Weirs. in IAHR$A P D$. 2010. Auckland, New-Zealand.

[10] Klopfenstein Jr, R., Air velocity and flow measurement using a Pitot tube. ISA Transactions, 1998. 37(4): p. 257-263.

[11] Ouamane, A. \& Lempérière, F. Nouvelle conception de déversoir pour l'accroissement de la capacité des retenues des barrages. in Colloque international sur la protection et la préservation des ressources en eau. 2006. Bilda, Algeria. 